\title{
Injusticias epistémicas y crisis ambiental
}

\author{
Epistemic Injustices and Environmental Crisis \\ Siobhan Guerrero Mc Manus* \\ Centro de Investigaciones Interdisciplinarias en Ciencias y Humanidades (СеIICH), Universidad \\ Nacional Autónoma de México, Ciudad de México, México \\ ORCID: https://orcid.org/0000-0002-3882-6217 \\ ISSN-OI85-4259; e-ISSN: 2007-9I76 \\ DOI: http://dx.doi.org/I0.28928/ri/90202I/aot2/guerreromcmanuss
}

\begin{abstract}
Resumen
El presente trabajo tiene como principal objetivo vincular la discusión en torno a las injusticias epistémicas que se ha ido desarrollando al interior de la epistemología social con una serie de problemáticas asociadas con la crisis ambiental contemporánea, en especial con sus aspectos más relacionados con el conocimiento. El término de injusticia epistémica fue originalmente acuñado por la filósofa Miranda Fricker y ha dado lugar a un fecundo campo de estudios que escudriña cómo las diversas posiciones sociales de los individuos que componen una sociedad los colocan en situaciones epistemológicamente asimétricas que puede generar dinámicas injustas como la de ignorar los testimonios de cierto estrato social. Sin embargo, este campo de estudios se ha concentrado excesivamente en las identidades de los individuos y ha dejado de lado dinámicas colectivas y aspectos contextuales como los relacionados con el medioambiente. Justamente la apuesta del presente texto consiste en superar estas limitaciones.

Palabras clave: injusticia hermenéutica, injusticia testimonial, narrativas, pensamiento ambiental, ecología queer.
\end{abstract}

\footnotetext{
Abstract

This paper aims to bring together the topic of epistemic injustices, so far developed within the field of social epistemology, with a collection of challenges associated with the contemporary environmental crisis, especially those aspects more related to knowledge. The term of epistemic injustice was originally coined by the philosopher Miranda Fricker and has given rise to a fruitful field of studies that scrutinizes how the different social positions of the individuals that make up a society place them in epistemologically asymmetric situations that can generate unfair dynamics such as a disregard for the testimonies of certain social strata. However, this field of inquiry has paid too much attention to the identities of concrete individuals and, thus, it has neglected collective dynamics and contextual aspects such as those related to the environment. It is precisely the objective of this text to overcome these limitations.

Keywordsः Hermeneutic Injustice, Testimonial Injustice, Narratives, Environmental Thought, Queer Ecology.
}

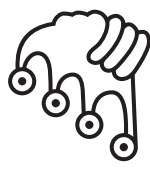

IZTAPALAPA

Agua sobre lajas

* siobhanfgm@gmail.com 


\section{Introducción}

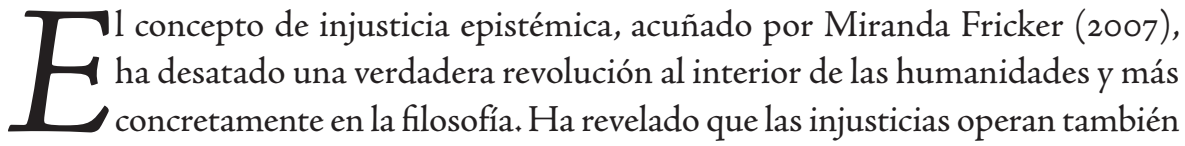
en el ámbito epistemológico, es decir, aquel que es propio del conocimiento y que, incluso, hay algunas modalidades de la injusticia que son ante todo injusticias en el ámbito de quién conoce, de quién puede conocer, pero también de quién puede ser escuchado, quién puede ofrecer testimonio y a quién va a creérsele cuando esto ocurra. Desafortunadamente, las preguntas anteriores suelen abordarse al poner en el centro del análisis las relaciones sociales en las cuales están situados los seres humanos; se atiende así a las relaciones de clase social, raza, ${ }^{1}$ etnicidad, género, orientación sexual, discapacidad, etc. Adicionalmente, hasta ahora la injusticia epistémica se ha descrito como un problema que ocurre entre individuos pertenecientes a distintas posiciones sociales y con ello se ha dejado sin analizar si dichas injusticias pueden también ocurrir en el diálogo intercultural, esto es, no se ha escudriñado la posibilidad de que tales procesos no sean exclusivos de las interacciones entre individuos y que, por ejemplo, puedan tener un correlato que se presente en el diálogo intergrupal y que sería por ende irreductiblemente colectivo.

Pareciera en este sentido que las injusticias son sobre todo un elemento característico de la convivencia social individual y que sólo ocurren en las interacciones entre seres humanos particulares. En otras palabras, las injusticias parecieran emerger principalmente de las asimetrías entre diversas posiciones sociales que ocupan distintas personas. Lo anterior, sin embargo, favorece una lectura de lo social cer-

1 Es importante señalar que en el presente texto no se emplea el término "raza" en su acepción biologicista. Por el contrario, siguiendo a Hochman (2019), cuando hablamos de raza aludimos a grupos que han sufrido procesos de racialización que son eminentemente sociales y que sin embargo invocan nociones biológicas para racionalizar este hecho. 
cana, por un lado, al individualismo metodológico y, por otro, a la creencia de que la sociedad humana es un todo autocontenido y ajeno al mundo natural. Ambos elementos señalan así una fuerte limitación de cómo hasta ahora se ha estudiado la injusticia epistémica.

El objetivo de este texto consiste en tomar distancia de la centralidad que se le ha asignado a las identidades en el análisis de las diversas formas de injusticia epistémica que se han documentado. En concreto, lo que se persigue es mostrar cómo el concepto de injusticia epistémica resulta central a la hora de comprender las relaciones entre el ser humano y el medioambiente. Así, se hará ver que un pensamiento interseccional (i.e., que cruza las diversas identidades y posiciones sociales) no puede ni debe restringirse a la esfera de las relaciones humanas como si estas se agotaran en las dinámicas identitarias y como si estas ocurrieran sin un contexto ambiental que también afecta y se ve afectado por dichas relaciones humanas. Asimismo, este texto pretende descentrar a los individuos para colocar en el centro a colectivos humanos que comparten prácticas y narrativas (Mundos-de-la-vida ${ }^{2}$ ) que dan lugar a una forma concreta de relacionarse con su entorno; este énfasis en la colectividad permitirá así atender a las preguntas que surgen en un diálogo intercultural que se cuestiona cuáles son las mejores formas de relacionarnos con nuestros entornos y cuyo objetivo precisamente es comparar cómo distintas sociedades construyen las relaciones ser humano-naturaleza.

De ese modo, se busca por un lado hacer un aporte a la epistemología social al mostrar cómo las relaciones entre diversas culturas y sus ambientes pueden estar ellas mismas atravesadas por procesos que generan injusticias epistémicas. Por otro lado, se busca contribuir a la filosofía ambiental al señalar cómo en nuestro afán por comprender las formas en las cuales diversas culturas interactúan con su medioambiente se corre sin embargo el riesgo de incurrir en fallas interpretativas que propician injusticias epistémicas que a su vez socavan nuestro afán de recuperar

2 El término "Mundo-de-la-vida", como se verá a lo largo de este trabajo, se emplea en un sentido técnico. Alude a un plexo de significatividad pragmática en la cual la materialidad de los objetos adquiere significancia (Guerrero Mc Manus y Mercado Reyes, 2019). El concepto abreva así de la tradición hermenéutico-fenomenológica (Marder, 2014) pero también de la forma en la cual las ideas de esta corriente fueron retomadas por la antropología (Mascia-Lees y Black, 2016). Sin embargo, si bien se puede entender como una posible acepción del término "cultura", habría que tener en mente que incluye las dimensiones materiales de esta. También habría que señalar que no remite a una noción cerrada o autocontenida que pudiera entenderse como si fuese una prisión epistemológica. 
e implementar formas de relacionarse con el entorno que resulten menos dañinas y que pueden sernos culturalmente ajenas.

Para alcanzar estos objetivos el texto se divide de la siguiente manera. A partir de la presentación del término de injusticia epistémica y de cómo ha ido evolucionando, se retoman los elementos de la ecología queer, pues esta disciplina humanística ha enfatizado la necesidad de incluir al medioambiente en toda reflexión interseccional. Una vez hecho esto nos concentramos en evidenciar cómo la noción de injusticia epistémica permite enriquecer el diálogo intercultural en el tema ambiental. Finalmente se exponen unas breves conclusiones.

\section{Injusticias epistémicas}

Han pasado más de diez años desde que Miranda Fricker acuñara el concepto de injusticia epistémica ${ }^{3}$ para nombrar dos instancias diferentes de injusticias relacionadas con el conocimiento (2007). Por un lado, buscaba señalar cómo en muy diversos tipos de injusticias hay adicionalmente una falta de un vocabulario interpretativo que permita reconocer que estamos ante una situación injusta; a este tipo de limitación hermenéutica la denominó precisamente injusticia hermenéutica para enfatizar cómo la carencia de una terminología adecuada para comprender una situación nos puede de hecho colocar en una posición tal que nos resulta imposible exigir un cambio, retribución o compensación porque ni siquiera somos capaces de identificar que lo que nos ocurre es injusto. Pensemos a modo de ejemplos en las consecuencias que acarrea la falta de acceso a la educación y cómo esto suele implicar un desco-

Vale la pena señalar que los trabajos más tempranos de Fricker se concentraron en el concepto de injusticia hermenéutica a la cual definió como "the injustice of having some significant area of one's social experience obscured from collective understanding owing to a structural prejudice in the collective hermeneutical resource" (Fricker, 2006; p. 100), esto es, como una injusticia en la cual un aspecto importante de nuestra propia vida social nos resulta opaco a causa de un prejuicio estructural en los recursos hermenéuticos colectivos. Nótese que la razón por la cual se considera que estamos ante injusticias emana de dos aspectos. Primero, porque este prejuicio genera marginalización e inequidad. Segundo, porque dicho prejuicio impide comprender un aspecto de la propia vida en la cual hay otras inequidades. Adicionalmente es importante mencionar el énfasis que Fricker le da a lo social al punto de acotar su concepto a este dominio. De igual modo pone en el centro de su definición a un individuo que, en este caso, es presentado desde la perspectiva de la primera persona. 
nocimiento de los derechos de los que gozamos al punto de hacer que en muchas ocasiones ignoremos el hecho de que poseemos garantías ante la ley que podríamos exigir sin que en ello medie condición alguna. De allí que, para continuar con el ejemplo, filósofos del derecho como Cruz Parcero (2007) mencionen que el lenguaje de los derechos humanos se ha vuelto una herramienta interpretativa fundamental en la convivencia cotidiana dada su capacidad de brindar herramientas para reconocer situaciones injustas; así, podríamos decir que el lenguaje de los derechos es un instrumento que permite evitar las injusticias hermenéuticas descritas por Fricker.

Por otro lado, Fricker también buscaba llamar la atención acerca de un segundo tipo de injusticia epistémica pero ahora en el ámbito del testimonio. Tradicionalmente la epistemología ha prestado poca atención al testimonio en parte porque se le considera una fuente de conocimiento secundaria y cuya importancia estaría subordinada al papel que juegan la percepción y el razonamiento en tanto fuentes primarias (Kusch, 2004). Asimismo, históricamente la epistemología se ha enfocado en las preguntas vinculadas a la justificación y validez de una aseveración, que servirían como piedras de toque para saber si estamos ante una mera creencia o ante conocimiento ${ }^{4}$ genuino. Empero, Fricker ha hecho ver que en numerosas ocasiones dirimir si algo cuenta como conocimiento, es decir, si está justificado y se le considera válido, requiere atender al testimonio de alguien que nos comunica un estado de cosas. Este proceso suele poner en juego una evaluación de la credibilidad de quien nos comunica un hecho, sea este perceptual o de razonamiento, y en ese acto de evaluar su credibilidad suelen emplearse herramientas que no solo versan acerca del contenido informacional transmitido sino que evalúan el grado de veracidad del informante empleando elementos sumamente heterogéneos de entre los cuales se pueden identificar aspectos como el grado de experticia o acreditación que aporta una institución (Collins y Evans, 2009; Shieber, 2015). Sin embargo, en dicho proceso también pueden filtrarse sesgos sociales relacionados con la clase social, el género o la raza de quien brinda testimonio, de tal suerte que su credibilidad termina estando condicionada a sus identidades sociales, lo que en muchas ocasiones puede dar lugar a un escenario injusto.

En ambos casos la apuesta de Fricker consistía en mostrar que hay situaciones asimétricas, limitativas y que refuerzan las dinámicas opresivas -de allí que se les califique como injusticias- que estarían vinculadas a cómo nuestras identidades sociales afectan diversos procesos asociados con el conocimiento, de tal manera que vulneran la capacidad de ciertos sujetos para adquirir conocimiento, analizar un

4 En este texto los términos saber y conocimiento se emplean como sinónimos. 
determinado escenario o describir exitosamente una situación que están viviendo. Es aquí donde también se aprecia fuertemente el énfasis individualista e identitario del propio proyecto de Fricker.

Sea como fuere, el trabajo de Fricker fue rápidamente reapropiado por filósofas interesadas en los cruces entre epistemología e identidad; esto se ilustra, por ejemplo, al atender a la forma en la cual la teórica Kristie Dotson (20iI) retomó los trabajos de Fricker. Esta filósofa se especializa en cómo las identidades afrodescendientes se han visto afectadas en el ámbito testimonial por las diversas facetas del racismo. Este trabajo la ha llevado precisamente a subdividir las injusticias testimoniales en dos tipos. Por un lado reconoce las injusticias asociadas con el silenciamiento, es decir, aquellas en las cuales la voz de una persona es desestimada, ignorada o puesta en entredicho a causa de su identidad; esto suele ocurrir, por ejemplo, cuando las mujeres negras denuncian violencia sexual o doméstica o cuando las personas de color se quejan de la discriminación y son ignoradas. En claro contraste a este tipo de injusticia estaría un segundo grupo de afectaciones testimoniales en las cuales los propios sujetos simplemente guardan silencio, atragantamiento epistemológico lo denomina Dotson, ya que saben que su testimonio no será atendido e incluso es posible que les ponga en riesgo al testimoniar $y$ denunciar vivencias que pueden ser acalladas por mecanismos violentos.

En cualquier caso, este es meramente un ejemplo de cómo el trabajo de Fricker ha sido reapropiado. Quizás la obra colectiva que mejor ilustra la recepción del concepto de injusticia epistémica y su posterior aplicación en casos tan diversos como los estudios poscoloniales, decoloniales, queer, feministas, transfeministas, de la discapacidad, etc., sea precisamente la compilación de ensayos editada por Ian James Kidd y colaboradores (2017; véase también Pohlhaus, 2017 y Guerrero Mc Manus y Muñoz Contreras, 2018). En esta obra el término de injusticia epistémica es releído a la luz de diversas metáforas que permiten extenderlo para abarcar nuevos tipos de interacciones sociales. Sobresalen así las lecturas en las cuales la injusticia epistémica es leída como (i) una afectación de la labor cognitiva, (ii) una deficiencia contractual, (iii) una falla en la justicia transaccional, distributiva o contributiva $y$, por último, (iv) un vicio.

De manera sucinta, pensar la injusticia epistémica en tanto una afectación de la labor cognitiva implica reconocer dos aspectos importantes. Primero, que conocer requiere un esfuerzo, esto es, la realización de un trabajo. Segundo, que como en todo trabajo existe una división de este que da lugar a especializaciones y dependencias epistémicas/testimoniales. Por lo anterior es que sería posible llevar a cabo una explotación de la labor cognitiva ajena al apropiarnos de su esfuerzo sin reconocerlo; 
esto puede ocurrir cuando se generan escenarios como los descritos bajo el rótulo de extractivismo identitario en los cuales las vivencias de un grupo se convierten en conocimiento objetivado que una serie de expertos retoman sin reconocer que no han sido ellos mismos quienes lo han creado. Un ejemplo claro es cuando los antropólogos se apropian de reflexiones creadas por personas de color en las que estas últimas reflexionan en torno al racismo que experimentan. En este caso operaría no únicamente una instancia de apropiación de la labor cognitiva ajena sino también una invisibilización de dicho esfuerzo, lo cual podría considerarse un segundo tipo de injusticia epistémica. Por último, dentro de la lectura de la injusticia epistémica en tanto una afectación de la labor cognitiva podemos encontrar prácticas de sabotaje del esfuerzo cognitivo ajeno, como cuando se destruyen y desarticulan las estructuras cognitivas de una comunidad entera en situaciones usualmente asociadas con dinámicas coloniales.

En el segundo caso, de la injusticia epistémica como deficiencia contractual, estamos ante una situación quizás mucho más cotidiana e intuitiva en la cual un contrato cognitivo entre dos individuos termina siendo vulnerado por medio de la fuerza o de las dinámicas de opresión social en las cuales están inmersos dichos individuos. Piénsese aquí cómo en un ejercicio de dar y pedir razones dentro de una práctica argumentativa puede sin embargo terminarse invocando la fuerza o la opresión en tanto mecanismos de resolución de un debate que debió mediarse por un ejercicio deontológico de proporcionar argumentos para adquirir acreditación/credibilidad y dar explicaciones cuando estas sean solicitadas si además deseamos mantener dicha acreditación/credibilidad (sobre las relaciones entre deontología, argumentación y poder véase Rouse, 1994). Este contrato epistémico en el cual se accede a un mecanismo dialógico basado en la argumentación se vería vulnerado cuando se emplean elementos como la fuerza o la discriminación para desacreditar a un oponente; ello sería por tanto una instancia de injusticia epistémica contractual.

En el tercer caso tendríamos diversas formas de comprender la justicia. Estas acepciones estarían cercanas al enfoque de las capacidades y el desarrollo humano y permitirían concebir la justicia en diversos ejes: transaccionales o conmutativos, distributivos, contributivos y retributivos. En principio las tres primeras acepciones podrían emplearse para construir nociones de injusticia epistémica inspiradas en estos. La injusticia epistémica conmutativa sería básicamente la ya descrita en el aparatado anterior pero aquellas vinculadas con la distribución o contribución implicarían formas novedosas. En el caso de la injusticia epistémica distributiva estaríamos ante fallos en la distribución de la credibilidad que no tienen elementos que los justifiquen; aquí por ende cabría distinguir entre grados de credibilidad asociados 
con diversos grados de experticia avalados por instituciones como las universidades, por un lado, y grados de credibilidad asociados a sesgos sociales como el racismo, el sexismo, el clasismo, por otro. Desde luego que esta distinción no es tan nítida pero su fortaleza es indicativa, ya que señala que no toda distribución asimétrica de la credibilidad sería sospechosa, y solo aquellas que no puedan justificarse serían por ende objeto de sospecha. Por otro lado, al hablar de una falla contributiva se enfatiza cómo ciertas identidades suelen verse excluidas de espacios académicos que son asimismo centros generadores de saberes; ello pasa por ejemplo con personas indígenas que no dominan el español o con personas con discapacidades motrices o visuales. En estas situaciones se ven limitadas en su condición de agentes epistémicos productivos y sus voces son así sistemáticamente excluidas.

Por último, concebir la injusticia epistémica como un vicio permite contrastarla con virtudes que podrían fomentarse al interior de una institución. Valores como la inclusión, el respeto, la tolerancia o la democratización del saber servirían así como importantes contrapesos a un vicio que está ampliamente presente en muchas de nuestras prácticas cognitivas. Serviría asimismo para enfatizar el carácter nocivo y sesgante de las injusticias epistémicas.

Ahora bien, al llegar a este punto podríamos afirmar que la importancia del concepto de injusticia epistémica va resultando cada vez más clara y que sus extensiones se revelan como herramientas provechosas en el proceso de comprender las formas en las cuales la opresión y la discriminación afectan aspectos epistémicos varios. Sin embargo, todas esas extensiones revisadas hasta ahora revelan de igual manera que la inmensa mayoría de los teóricos de la injusticia epistémica se han enfocado en relaciones entre individuos descartando así la posibilidad de extender este marco a dinámicas de índole colectiva. ${ }^{5}$ De igual manera han ignorado la posi-

5 Durante el proceso de arbitraje del presente artículo una de las personas que realizaron el referato señaló que consideraba injusta mi acusación de que el trabajo de Fricker y, en general, la forma en la cual se ha construido el concepto de injusticia epistémica, esté presa de un sesgo individualista. Afirmó que Fricker reconoce dinámicas grupales en, al menos, dos sentidos. Por un lado, porque las identidades conforman grupos; por ejemplo, las personas de color, los discapacitados, las personas de la diversidad, son ejemplos de grupos construidos identitariamente y que sin duda sufren sesgos estructurales. Por otro lado, porque las injusticias de las cuales habla Fricker afectan a una posición de sujeto y no a una persona en lo individual; de allí que dichas injusticias afecten a colectividades enteras. Sobre esta inquietud quisiera señalar lo siguiente: Primero, ninguno de los dos escenarios planteados es un genuino contraejemplo a lo aquí dicho, pues en ambos casos los grupos son o bien meros agregados de individuos (primer caso) 
bilidad de emplear este término para iluminar las dinámicas epistémicas que median nuestra relación con la naturaleza. En la siguiente sección justamente se presentará un enfoque que expande el análisis interseccional al ámbito ecológico y que puede permitir una lectura no individualista de la injusticia epistémica.

\section{Interseccionalidad y ecología queer}

Como hemos visto, gran parte de las concepciones en torno a la injusticia epistémica colocan en el centro de su reflexión las diversas identidades sociales que ocupan las personas. Puede sostenerse en este sentido que este marco analítico es de corte interseccional precisamente por su interés por indagar cómo diversas posiciones sociales o identidades generan obstáculos o privilegios en la convivencia, en general, y en el ámbito epistémico, en particular. Recordemos aquí que la interseccionalidad es un término acuñado por Kimberlé Crenshaw (1991) y cuyo cometido consistía en recuperar diversos análisis del feminismo negro, en especial los contenidos en los trabajos de Audre Lorde, con el fin de hacer ver cómo el cruce de dos o más identidades no podía comprenderse de manera aditiva o a la usanza de un cálculo vectorial. Esto es, que la experiencia de una mujer lesbiana de color no era el resultado de combinar las experiencias de un hombre de color, una mujer blanca y un hombre homosexual; las identidades, como sostuvo Crenshaw, no operan de esta manera.

o bien posiciones que satisfacen individuos pero no colectivos (segundo), es decir, se pueden comprender bajo una óptica propia del individualismo metodológico. Segundo, este trabajo busca defender la tesis de que hay sujetos irreductiblemente colectivos que no pueden desagregarse en una mera colección de individuos; aquí sugerimos que los Mundos-de-la-vida serían un ejemplo de una producción irreductiblemente colectiva que denota a un sujeto de esta índole y que no es de autoría de ningún individuo y tampoco se agota en las creencias o acciones de algún individuo en concreto. Así, cuando un Mundo-de-la-vida es presa de una injusticia epistémica esto no puede equipararse a las injusticias que sufre un conjunto determinado de individuos particulares. Tercero, en este sentido hay que tener en cuenta los propios ejemplos que da Fricker y en los cuales siempre estamos ante una persona que sufre una injusticia; incluso si sufre dicha injusticia a causa de su pertenencia a un grupo, no es el grupo el que sufre tal o cual injusticia particular. Lo que aquí se defiende es que es posible que grupos enteros, en tanto colectividades irreductibles, sufran injusticias epistémicas concretas. Ello es diferente a afirmar que cada miembro de un grupo sufre injusticias de un mismo tipo ya que esto, en cualquier caso, no implica que todos sufran la misma injusticia ni que la sufran como grupo pues son los derechos de uno u otro individuo los que se ven vulnerados. 
Por ello mismo es que Crenshaw realizaba una importante crítica al movimiento feminista pero también al movimiento por los derechos de los afroamericanos señalándoles que era necesario romper con la presunción de que estábamos ante sujetos políticos homogéneos. Esto último nunca ocurre y es potencialmente muy dañino en aspectos tales como la representación política o mediática de las minorías y otros grupos subalternizados.

La interseccionalidad, en tanto marco analítico, inauguró toda una nueva forma de articular los análisis feministas al dejar de lado la idea de sujetos políticos con límites claros y experiencias homogéneas. En cierto sentido su influencia se hizo presente en los trabajos de Fricker, Dotson y otros teóricos precisamente por el énfasis que todos ellos le dieron a categorías como raza, clase, etnia, sexo, género, etc. En el caso de Fricker, por ejemplo, gran parte de su análisis abreva de los estudios acerca de cómo las diversas identidades potencian o limitan la agencia de una persona y en esto hay que ser muy claros dado que el nivel de análisis es justo ese -la persona-, pues es esta la que encarna dos o más identidades. Esto mismo ocurre con Dotson, quien también recupera este enfoque y su énfasis en los individuos. De allí que se afirme que en el corazón de los análisis en torno a la injusticia epistémica se encuentre un entendimiento de corte interseccional sobre las identidades y los sistemas de opresión que las producen. De allí también que exista una profunda coincidencia en su apuesta por un individualismo metodológico que deja de lado formas alternativas de comprender las identidades o incluso formas alternativas de hacer interseccionar las categorías de interés. $\mathrm{Y}$, finalmente, esto también explicaría por qué otro tipo de variables de interés -e.g. el entorno ambiental en el que se encuentra emplazada una persona- han sido poco incluidas en la inmensa mayoría de aproximaciones interesadas tanto en la interseccionalidad como en la injusticia epistémica.

Precisamente por esta profunda coincidencia es que podríamos suponer que un replanteamiento diferente de la interseccionalidad podría también servir de base para una concepción alternativa de lo que puede ser la injusticia epistémica. Y es aquí donde sería posible recuperar los aportes de la ecología queer, pues esta implica una forma diferente de comprender la interseccionalidad. Esta disciplina nació de la recepción crítica de los trabajos de los biólogos evolutivos Joan Roughgarden (2013) y Bruce Bagemihl (1999); en ambos casos el interés de estos científicos consistió en poner en duda la presunta heterosexualidad de los animales no humanos haciendo ver que esta suposición era más bien un sesgo sistemáticamente proyectado sobre los seres no humanos bajo la presunción de que sus vidas estaban gobernadas por imperativos reproductivistas. Observaciones más cuidadosas y modelos evolutivos más sofisticados, aseveraban estos autores, permitían alejarse y cuestionar este hete- 
rosexismo naturalizado haciendo ver que en el reino animal son muy comunes las interacciones sociales y sociosexuales entre organismos del mismo sexo y que incluso los despliegues conductuales no están siempre estereotipados por sexo.

La recepción de estas ideas al interior de las humanidades llevó a que estas se combinaran con articulaciones teóricas nacidas en la crítica literaria que tenía al medioambiente como su objeto de análisis. Esta corriente, la ecocrítica, se enfocaba en comprender los modos en los que el medioambiente figuraba en las novelas y otros productos culturales de tal manera que había relatos en los cuales la naturaleza aparecía como indómita y salvaje, apta por tanto para masculinidades hegemónicas pero no así para otros tipos de cuerpos y sujetos (Gaard, 1997). En otros relatos la naturaleza aparecía como apacible, un lugar para escapar del frenesí decadente de la civilización y, por ende, siendo fundamentalmente un espacio de relajación para personas enfermas o subjetividades juzgadas como débiles. Dicho esto, el interés de la ecocrítica consiste en revelar cómo la naturaleza nunca se nos presenta "en sí misma" sino a través de simbolizaciones y narrativas que la revisten de ciertos atributos que la hacen más o menos habitables para cierto tipo de sujetos; usualmente, los valores atribuidos a la naturaleza posibilitan o imposibilitan el acceso de ciertos cuerpos que también están revestidos de otros valores que serán claves para poder encarar una naturaleza hostil e indómita o bucólica y campestre.

Estas ideas desde luego no eran nuevas y ya en los estudios de género con interés en las lógicas del espacio y la distribución de cuerpos había un interés por dilucidar cómo los espacios de cualquier tipo están revestidos de valores que llevan a que cierto tipo de cuerpos puedan ganar acceso mientras que otros tantos son excluidos. Ahora bien, hay ocasiones en las cuales grupos minoritarios partidarios del separatismo han construido dinámicas de ordenamiento espacial de los cuerpos que han llevado a una segregación con el afán de producir espacios seguros. En ambos casos el estudio de las dinámicas espaciales del género $-y$ sus cruces con la raza, la clase, la nacionalidad, etc. - se revela como un objeto de análisis fundamental si queremos comprender cómo las jerarquías se traducen en limitaciones en la movilidad de ciertos cuerpos, limitaciones que son una forma fundamental de disciplinamiento del cuerpo generizado (sobre esto véanse los trabajos de Mortimer-Sandilans y Erickson, 20IO; véase también Mascia-Lees y Black, 2016).

Así, la ecología queer es una disciplina en la cual se combinaron estos tres enfoques disciplinarios para dar lugar a un saber cuyo objetivo es analizar los modos en los que el género estructura nuestra relación con el medioambiente y cómo se proyecta incluso a entidades no humanas como los animales, las plantas y los ecosistemas. Ello ha dado lugar a una aproximación en la cual se desnaturaliza la 
presunción de una naturaleza reproductivista, funcionalista y complementarista en la cual la vida sexual de los no humanos siempre obedece a lógicas heterosexuales encaminadas a la producción de descendientes. Por el contrario, la ecología queer ha señalado la existencia de una naturaleza queer, es decir, torcida, no siempre gobernada por el reproductivismo, el funcionalismo o las lógicas complementaristas; en esta naturaleza hay interacciones sexuales lúdicas o socio-sexuales cuyo fin es o bien el placer o bien la creación de vínculos homosexuales que terminan por ser importantes para la vida social de los animales no humanos. Asimismo, este proceso opera una curiosa naturalización de lo queer que quizás podría describirse de una manera más precisa como un descentramiento del ser humano en tanto única entidad poseedora de una vida sexual que desborda al funcionalismo, el reproductivismo y la complementariedad.

Esta doble naturalización/desnaturalización de la sexualidad y de lo queer ha llevado a cuestionar no solo las formas en las cuales las representaciones culturales valorizan a la naturaleza, por ejemplo en la novela o el cine, sino también cómo las ciencias y otros saberes describen los espacios naturales y los ecosistemas vía relatos, narrativas o juicios de valor que inadvertidamente generizan estos espacios. Aquí es importante señalar que las formas en las cuales se reviste de valores a través de un producto literario no son necesariamente las mismas que encontraremos en un artículo científico o modelo explicativo y que por ende es importante tener en claro cómo operan los distintos medios en los cuales se representa lo natural.

Afortunadamente sí hay al menos un núcleo de herramientas comunes que pueden movilizarse ya sea que nuestro interés sea la crítica literaria, la deconstrucción del heterosexismo en las explicaciones ecológicas y evolutivas de la conducta animal o una mejor comprensión de la política espacial de los cuerpos generizados. Estas herramientas se concentran en el análisis de las narrativas, ya que estas son importantes en el ámbito explicativo pero también dada su capacidad de organizar experiencias e interpretar situaciones, sean estas ficticias o no. Ello ocurre porque las narrativas son obviamente centrales para diversos productos culturales como la novela o el cine (Bal, 2009) pero son igualmente centrales en la construcción de explicaciones científicas (Roth, 1989, 2017; Richards, 1992) incluso si estas apelan a modelos matemáticos o diagramas. Finalmente, las narrativas son centrales a la hora de articular Mundos-de-la-vida, esto es, las formas en las cuales una sociedad comprende su entorno (sobre esto véase Guerrero Mc Manus, 2018; Guerrero Mc Manus y Mercado Reyes, 2019; véase asimismo Marder, 2014).

Y es gracias a este énfasis puesto en la narrativa que la ecología queer puede replantear la interseccionalidad en tanto un ejercicio de cruce de relatos y no como 
cruce de identidades. ${ }^{6}$ Elaborar esta idea requiere tomar en cuenta que, por ejemplo, un animal no humano claramente no puede ser descrito apelando a identidades por el hecho trivial de carecer de ellas. Sin embargo, es claro que una mirada eurocéntrica, heterosexista o colonial bien puede hacerse presente en la forma como se describe la conducta o la morfología de un organismo. Y esto mismo puede decirse de la manera en la cual describimos espacios naturales, ecosistemas e incluso mundos ficticios. En todos estos casos la interseccionalidad bien puede aplicarse a pesar de que propiamente hablando no estamos ante individuos con identidades concretas sino ante seres que o bien carecen de ellas o son tan deslocalizados - por ejemplo, un bosque- que ni siquiera podrían pensarse como individuos sin reducir este término a un sinsentido. Empero, el hecho de que estemos ante una colección de seres que en principio parecían inapropiados para un análisis interseccional no implica desde luego que estos seres no puedan ser abordados y descritos por puntos de vista que sí implican un sujeto situado y por ello colocado en una rejilla social de identidades y posiciones. Aquí opera por tanto un desplazamiento de la identidad de los sujetos analizados a la identidad de quién describe y categoriza, organiza o explica. Esta es sin duda una forma en la cual la interseccionalidad es reinventada por la ecología queer en tanto una herramienta de análisis aplicable a seres que no son individuos humanos con identidades.

Un movimiento alternativo que no es propiamente queer pero que sí es igualmente interesante lo encontramos también en esfuerzos que no se centran en la perspectiva o focalización que provee la voz autoral o narrativa sino en el sujeto (entendido como tópico) de la narración; así, por ejemplo, hay narrativas cuyo tópico es la raza o la clase sin que se centren en ningún individuo concreto y estas narrativas se pueden interseccionar con narrativas centradas en el género. En estos casos podemos seguir explicaciones narrativas de índole histórica que toman una u otra categoría como su tópico central y que ven cómo una categoría permite entender el devenir histórico de una serie de fenómenos; la interseccionalidad aquí no opera a modo de un eje de análisis que atienda a las identidades de los sujetos bajo estudio

6 Es menester aclarar en este punto que podría haber cierto debate a la hora de afirmar que la interseccionalidad es una herramienta conceptual cuyo principal objetivo consiste en mostrar cómo el cruce de identidades muestra el carácter internamente heterogéneo de cada categoría. Si bien esto ocurre, podría sostenerse que este es un resultado derivativo del interés por mostrar cómo se jerarquizan diversas identidades. Para los fines del presente artículo esta es una discusión tangencial pues lo que me interesa es mostrar una forma distinta de comprender la interseccionalidad al poner el énfasis en los tópicos de las narrativas y no ya en las identidades y sus jerarquías. 
pero tampoco como un intento por situar la voz autoral o narrativa sino que opera al combinar diversos tópicos. A modo de ejemplo, una narrativa acerca de la historia de la silvicultura en Nuevo México puede enfatizar el papel que jugó la eugenesia y la raza en la creación de los parques nacionales en los EUA; estos parques, como se ha mostrado, fueron creados con el afán de proteger a la naturaleza del "uso rapaz" por parte de ciertas poblaciones racializadas para que así las poblaciones blancas pudieran continuar disfrutando de esta naturaleza presuntamente prístina (Kosek, 2006). En este ejemplo la historia de la raza se cruza con la historia del pensamiento ambiental y la historia de la eugenesia con la historia de la silvicultura; así también, esta narrativa muestra cómo las poblaciones hispanas son objeto de un trato a la vez racista, xenófobo y aporafóbico que ha llevado a que se les juzgue en tanto depredadores ambientales incluso pasando por alto el papel que juegan grandes corporaciones en la destrucción de esos mismos bosques.

En cualquier caso, hemos llegado al punto que nos interesaba y que consistía en señalar cómo la ecología queer permite reinventar la interseccionalidad en tanto una herramienta analítica aplicable a sujetos difusos, no humanos y carentes de identidad. Si ello es posible es precisamente porque el análisis puede desplazarse para analizar la perspectiva autoral o narrativa o para atender a cómo diversos tópicos se entrecruzan en un relato. Es justo esta idea la que servirá de base en la siguiente sección para trasladar las nociones de injusticia epistémica expuestas anteriormente a un estudio de nuestras relaciones con el medioambiente.

\section{Injusticia epistémica y medioambiente}

Se ha criticado mucho, desde mi punto de vista de manera injustificada, la atención que han recibido las narrativas y los textos en los análisis de corte posestructuralista. ${ }^{7}$ Se ha afirmado que este giro textualista pierde de vista los objetos, la materia o las relaciones causales y que reduce todo a un mero efecto de la escritura. Quizás esto último pueda ser cierto de algunos autores pero sin duda sería problemático acusar de textualismo a una filósofa como Donna Haraway (2013a, 2013b), referencia indiscutible al interior de la ecología queer. En este sentido, es bien sabido que Haraway fue una pionera en los análisis de corte material-semiótico que enfatizaron

$7 \mathrm{Al}$ realizar esta afirmación tengo en mente sobre todo corrientes como la ontología orientada a objetos o el nuevo materialismo feminista. Para introducirse a estos tópicos se recomiendan Harman (2018) y Alaimo y Hekman (2008). 
cómo los elementos simbólicos y narrativos están todo el tiempo imbricados con las evidencias científicas, las observaciones, los instrumentos y demás herramientas de observación, etc.; lo que esta imbricación produce es justamente un plexo de significatividad pragmática en la cual la materialidad de los objetos adquiere significancia precisamente por el elemento semiótico que la envuelve y le otorga así un sentido. Pero este sentido no es una ficción textual, sino que acompaña a la capacidad interventiva y causal de dichos objetos. Es esta noción de narrativa la que nos interesa en este texto.

Ello es así ya que los primeros trabajos que recuperaron herramientas de corte hermenéutico al interior de la antropología y demás humanidades, con autores como Clifford Geertz (Mascia-Lees y Black, 20I6), se enfocaron principalmente en los elementos semióticos y dejaron de lado el análisis materialista que Haraway sí recupera y que permite evadir las acusaciones tanto de textualismo como de la mucho menos conocida pero quizás más peligrosa posibilidad de postular a los Mundos-de-la-vida como sistemas simbólicos plenamente autocontenidos. La apelación a una materialidad con la cual se imbrican los elementos semióticos pero sin que unos u otros subsuman a su contraparte abre la posibilidad de pensar estos mundos como abiertos ante las experiencias novedosas o las vivencias de otras culturas. Así, estos Mundos-de-la-vida serían fundamentales pues son los organizadores de la experiencia, de los fenómenos, sin que ello implique que operen a modo de prisiones epistemológicas.

Más todavía, estos Mundos-de-la-vida pueden pensarse en tanto narrativas de corte material-semiótico y que de alguna forma le pertenecen irreductiblemente a un colectivo de sujetos/sujeto colectivo. Esta dimensión colectiva emergería de varios elementos de entre los cuales cabría destacar el carácter público y social de los significados pero, de forma mucho más importante, el hecho de que las narrativas suelen ser las portadoras de los relatos fundacionales de los grupos sociales transmitiendo así las formas permitidas de ser sujeto en una comunidad dada, sus valores, sus formas de interactuar y concebir el mundo y a sí mismos, etc. Es decir, las narrativas son a la vez un producto de un nosotros, de un sujeto plural, que a la vez emerge de esta cosmovisión compartida (Guerrero Mc Manus, 2018; Guerrero Mc Manus y Mercado Reyes, 2019; Wilson, 2005).

Sería justamente a la luz de esta forma de comprender las narrativas como radicalmente colectivas e irreductibles a una vivencia individual -pues de hecho fungirían como un mecanismo de producción del sujeto mismo-que podríamos sostener que estas narrativas configuran una relación con el mundo y con la crisis ambiental que haría imposible un listado pretendidamente objetivo y universal de 
todos los costos que acarrea la debacle ecológica que vivimos; ello ocurriría ya que diversos objetos poseen diversas significancias para diversos Mundos-de-la-vida y lo que se pierde al, por ejemplo, perder un bosque no es solo el bosque sino lo que este era para los Mundos-de-la-vida que lo habitaban.

En cualquier caso, uno de los grandes retos para el pensamiento ambiental contemporáneo consiste en esto último, es decir, en reconocer que la crisis ambiental debe ser leída en clave multicultural y ello no solo para ser políticamente correctos, sino para aquilatar los costos que estamos confrontando. De igual manera, esta perspectiva multicultural puede ser fundamental para encontrar nuevas formas de cohabitar el planeta pues como lo han mostrado teóricas como Anna Tsing (20II), un área natural puede ser pensada a modo de un espacio prístino y en el cual ningún ser humano debiera morar o también puede ser concebido como un espacio social donde la cohabitación es un motor de la permanencia de la biodiversidad. Importa así cómo se habita el mundo, cómo se le concibe y narra pero en un sentido material-semiótico.

De esta dimensión multicultural es de donde se sigue la imperiosa necesidad de saber articular diálogos entre diversas cosmologías y es allí donde la epistemología del testimonio y sus análisis en torno a las injusticias epistémicas pueden empezar a figurar de manera central. Más concretamente, al concebir la crisis ambiental en tanto algo que le ocurre a una multiplicidad de sujetos colectivos y no a esa ficción llamada "ser humano" es que podemos apreciar la importancia que va a jugar una comunicación eficiente entre diversas cosmologías. Así, por ejemplo, podríamos aplicar los conceptos de injusticias hermenéuticas y testimoniales e incluso las subdivisiones propuestas para este último término para comprender diferentes desafíos que hoy nos confrontan. Trabajos anteriores ya han señalado cómo las injusticias hermenéuticas pueden hacerse presentes en al menos dos modalidades (Guerrero Mc Manus y Mercado Reyes, 2019). Por un lado, cuando una cultura o Mundode-la-vida carece de las herramientas interpretativas para comprender el carácter global y sistémico de la crisis ambiental; esto puede ocurrir simplemente porque la epistemología asociada a dicha cosmovisión no tiene los elementos necesarios para imaginar un fenómeno de esta escala.

Una segunda posibilidad, mucho más grave, es que una comunidad sufra los efectos de una serie de dinámicas globales que ahora la azotan gracias a las dinámicas neocoloniales y extractivistas que suelen acompañar el deterioro ambiental; cuando este proceso produce pobreza y marginalización también tiene como efecto el limitar y afectar la consolidación epistemológica de quienes allí habitan, lo que muy probablemente conduce a deficiencias hermenéuticas $y$, a causa de esto, a injusticias 
del mismo tipo. En esta segundo situación dicha comunidad puede que comprenda que se está viendo afectada pero quizás no logra articular completamente un diagnóstico acerca del grado de afectación que sufre.

En ambos casos esta deficiencia interpretativa origina un proceso agnogenético, es decir, generador de ignorancia, ya que se carece de las herramientas necesarias para comprender lo que se vive (Proctor y Schiebinger, 2008). Este proceso muy seguramente se vería exacerbado dada la tendencia a construir discursos científicos sumamente herméticos y que resultan difíciles de asimilar fuera de los centros generadores de saberes.

Ahora bien, las injusticias testimoniales también pueden hacerse presentes cuando, por ejemplo, se privilegia un lenguaje técnico y de corte académico a la hora de narrar las afectaciones ambientales que sufre una comunidad. Es más, incluso podríamos sostener que uno de los ejes que favorecen y mantienen el colonialismo epistemológico emana precisamente de esta asimetría en la confianza y credibilidad que se le deposita a un discurso. Lo anterior no busca defender una suerte de relativismo extremo en el cual todo discurso debiera gozar de la misma credibilidad sino simplemente señalar un hecho mucho más pedestre: otorgarle cierta credibilidad a un saber no hegemónico no implica juzgarlo igualmente verosímil que un saber científico pero sí implica tomar distancia de la idea de que los discursos no científicos poseen nula credibilidad. Esto último casi que podría juzgarse como un vicio epistémico muy frecuente que produce injusticias testimoniales y que lleva al silenciamiento o incluso el atragantamiento de múltiples comunidades. Peor aún, este vicio acrecienta el colonialismo epistémico pues no solo periferaliza a otros saberes sino que literalmente los reduce a mitos y obliga a dichas comunidades a articular sus vivencias a través de un relato objetivado y propio de las ciencias, incluso a costa de poder enunciar los costos que la crisis ambiental tiene para su Mundo-de-la-vida.

Y es en este último punto donde el presente artículo busca hacer su mayor aportación al movilizar algunas de las diversas metáforas expuestas en la sección segunda para señalar formas en las cuales los diálogos multiculturales pueden fracasar incluso cuando tienen las mejores intenciones y compromisos éticos. Ya se ha señalado el vicio en tanto un ejemplo de ello pero en lo que resta de esta sección quisiera concentrarme en la injusticia testimonial como afectación de la labor cognitiva y en la injusticia testimonial como una falla en la justicia contributiva.

En el primer caso, si recordamos lo ya expuesto, se contemplaban tres posibilidades: extractivismo, invisibilización y sabotaje. Con relación al primer término es importante no perder de vista que aquí no estamos hablando del extractivismo como 
usualmente se le entiende en cuestiones ambientales, esto es, como la sustracción de recursos naturales dentro de lógicas económicas capitalistas. Al interior de los estudios sobre la injusticia epistémica el término extractivismo suele emplearse en sentido metafórico y se refiere a la apropiación de experiencias y saberes locales por parte de elites epistémicas -usualmente investigadores provenientes de diversas instituciones de investigación o educación superior- cuyo objetivo usual es generar productos académicos o tecnológicos y muy rara vez estrategias que de facto beneficien a las poblaciones bajo estudio. Es muy común, por ejemplo, que las vivencias de personas afrodescendientes, LGBT, con discapacidad, etc., sean retomadas en múltiples investigaciones que, sin embargo, no benefician en último término a las personas que las contaron. A esto nos referimos cuando hablamos del extractivismo en tanto una forma de injusticia epistémica.

En casos extremos el extractivismo da lugar a formas de apropiación de saberes en las cuales el conocimiento generado localmente es re-descrito y presentado como si fuera un producto concebido por los investigadores que realizan tal re-descripción. Aquí el extractivismo se cruza ya con la invisibilización dado el borramiento del sujeto que originalmente llevó a cabo tal esfuerzo cognitivo e incluso con el sabotaje si a la postre se prohíbe a dicha comunidad el uso de un saber o técnica localmente generado con la excusa de que ya no es, finalmente, su "propiedad". Esta práctica desafortunadamente no ha sido inusual al interior de las humanidades (o para el caso de las ciencias ambientales) y es por ello que hoy en día muchos antropólogos favorecen la producción de conocimientos a través de propuestas colaborativas en las cuales la distinción entre investigador e informante se abandone (sobre este punto véanse algunos de los trabajos recopilados en Haenn et al., 2016). Asimismo, ha empezado a fomentarse la idea de que una producción ética del conocimiento no debe beneficiar únicamente a quien lo describe sino que debe atender a las necesidades de los propios informantes. La apuesta consiste en evitar que se den estas dinámicas de apropiación y en ciertos casos de mercantilización de un saber que fue producto de la labor cognitiva de un tercero.

En lo que respecta a los saberes ambientales, es claro que no estaríamos hablando, al menos no necesariamente, de un extractivismo de las experiencias identitarias de algún colectivo sino quizás de los saberes locales que un grupo humano ha ido articulando y que versan sobre el uso del territorio y sus recursos; el elemento identitario puede surgir si, por ejemplo, hay una dinámica de apropiación cultural en la cual un saber generado por un grupo indígena es reapropiado por alguien que justamente lo presenta como el fruto de su propio trabajo. Aquí habría que tener en cuenta la importancia de las narrativas y de los Mundos-de-la-vida, ya que muchas formas de 
conocimiento local no poseen un autor claro y son una suerte de saber colectivo que se transmite al interior de una comunidad. Así, este saber puede parecer mundano $-y$ esto en dos sentidos, ya que parece, por un lado, trivial $y$, por otro, un mero hecho bruto del mundo, al menos de ese Mundo-de-la-vida- para los miembros de una comunidad, algo que todos saben precisamente por su carácter colectivo; es quizás este elemento el que invita a apropiarse de un saber que en cierto sentido nadie reclama como propio, que nadie reclama como fruto de su labor individual. Empero, el hecho de que sea una suerte de bien común (Cruz Parcero, 2007) no implica que no se cometa una injusticia epistémica de corte extractivista e invisibilizante pues aquí el sujeto que se ve vulnerado es precisamente un sujeto colectivo, ya que los saberes que informan su cosmovisión son literalmente usufructuados por un tercero que no invirtió esfuerzo alguno en su generación y propagación.

Históricamente, la articulación de la modernidad en América Latina ha exhibido numerosos ejemplos de estas prácticas, ya que muchas formas de producción implementadas en la época de la colonia resultaron inadecuadas y fueron dejadas de lado en favor de sistemas híbridos que retomaban saberes locales; a este proceso se le ha denominado modernidad en capas para ilustrar que la colonia no necesariamente implicó la desarticulación y desmantelamiento de los saberes precolombinos, ya que en muchas ocasiones estos fueron subsumidos y recolocados dentro de las prácticas extractivistas coloniales, dando lugar a mecanismos mucho más eficientes que los originalmente traídos de Europa (Thomas, 2017). A la luz del marco teórico empleado en este texto podríamos sugerir que muchas de estas dinámicas de apropiación fueron claras instancias de injusticias epistémicas (y de otros tipos) en las cuales la labor cognitiva de un grupo fue invisibilizada y extraída en beneficio de los colonizadores, quienes a la postre terminaron incluso por sabotear las propias prácticas cognitivas de los grupos originarios a través de diversas formas de violencia.

Si este ejemplo de corte histórico nos parece útil entonces quizás pueda servir para fundamentar un renovado interés por el estudio de fenómenos como la bioprospección y la biopiratería a la luz de la noción de injusticia epistémica para así iluminar diversas prácticas que ocurren en las interacciones entre el medioambiente y diversos colectivos humanos que lo conceptualizan y habitan de modos diferentes. El extractivismo, la invisibilización y el sabotaje pueden ser elementos característicos de estos procesos en los cuales la labor cognitiva de un grupo humano es reapropiada y mercantilizada por alguien más.

Por otro lado, con respecto al segundo escenario en el cual se concibe a la injusticia epistémica en tanto una falla en la justicia contributiva, quizás un buen ejemplo de ello lo encontramos en el borramiento de la agencia epistémica de los pueblos 
originarios o de las comunidades que habitan un territorio. A diferencia de otros casos en los cuales falla la distribución, retribución o transacción de la credibilidad o del reconocimiento de la agencia de un sujeto, una falla en la justicia contributiva en el ámbito epistémico implica considerar a ciertos agentes como incapaces de realizar algún aporte cognitivo, esto es, se les juzga incapaces de contribuir y se les coloca en la posición de un mero beneficiario que será siempre un sujeto de asistencia. Esto puede ocurrir de muy diversas formas siendo la más común la afirmación explícita o implícita de que ciertos colectivos simplemente no tienen la formación suficiente para hacer un aporte sustancial y que la labor de los grupos más privilegiados debiera consistir en auxiliarlos e incluso rescatarlos de su propia ignorancia. Aquí pueden mediar elementos identitarios de corte racista o clasista, entre otros, pero esto también puede ocurrir al desdeñar los Mundos-de-la-vida no asociados a las cosmovisiones occidentales.

Empero muchos activistas medioambientales terminan por caer en dinámicas de este tipo, aunque esto no es privativo de activistas entusiastas que carecen de una perspectiva multicultural. Un ejemplo por demás claro de un tipo de dinámica como la anteriormente descrita fue denunciada por el antropólogo ambiental J. Peter Brosius en su afamado ensayo Endangered Forest, Endangered People. Environmentalist Representations of Indigenous Knowledge (1997, véase también Haenn et al., 2016). Como el propio Brosius lo narra, no es poco común que mucha de la antropología ambiental contemporánea, en un afán por proteger a los pueblos originarios y sus territorios, termine por representar a los primeros como seres profundamente espirituales y con una suerte de conexión mística con los segundos. El caso que este autor invoca hace referencia a una muy desafortunada descripción de diversas comunidades originarias de Malasia a las cuales se les buscó representar como un pueblo místico que tenía una relación reverencial que rebasaba por completo lo empírico y que revestía a todos los seres no humanos de su entorno con un halo de espiritualidad que daba lugar a dinámicas de conservación basadas en la adoración.

Lo trágico de esta situación es que dicha descripción romantizaba a los habitantes muy a la usanza del buen salvaje convertido ahora en ecologista y fomentaba la versión de que el sistema de creencias de estos pueblos era totalmente mágico e inescrutable para Occidente pero que aun así daba lugar a lógicas conservacionistas importantes. El propio Brosius tenía más de tres décadas de trabajo en esta localidad y escribió el ensayo antes mencionado justamente para hacer un llamado de atención a estas prácticas de romantización. Sus principales quejas consistían en señalar que esta descripción mistificaba y desmaterializaba el sistema de creencias, el conocimiento de estos pueblos; lo reducía a un mero mito ecológicamente útil. 
Ello implicaba no solo perder de vista la historia y la base empírica de estos saberes, sino también todo posible aprendizaje que pudiera dar lugar a mejores prácticas forestales. Su objetivo al señalar a estos puntos era hacer ver cómo en un afán por "salvar" a un pueblo y un territorio se caía en prácticas que romantizaban y mistificaban las creencias locales y que removían todo estatus de conocimiento al ignorar las prácticas materiales e interventivas asociadas con dichas creencias; ello borraba la agencia de estos sujetos pero también hacía imposible aprender acerca de sus modos de habitar el bosque de maneras sostenibles, pues esto último simplemente no se apreciaba si era una mera consecuencia de su espiritualidad y no de un profundo conocimiento de cómo explotar los recursos de su entorno.

Lo que yo quisiera recuperar de este caso es precisamente cómo lo que denuncia Brosius es una clara instancia de una injusticia epistémica en la justicia contributiva pues se borra la agencia epistémica de este pueblo y con ello se pierde de vista el carácter interventivo, empírico y material de su cosmovisión. El costo final de este movimiento no es solo la infantilización de este pueblo sino la imposibilidad de crear un diálogo multicultural en el cual los saberes de este pueblo pueda servir de base para prácticas forestales en ese y otros territorios.

Así, para cerrar, este segundo ejemplo ilustra de manera contundente cómo la noción de injusticia epistémica puede aplicarse no solo a las prácticas productivas de corte colonial y extractivista (algo que se hizo en esta misma sección con el caso de la modernidad en capas), sino también a las apuestas ambientalistas que buscan superarlas. En ambos escenarios vemos cómo la relación ser humano-naturaleza está mediada por Mundos-de-la-vida que distan mucho de ser meros relatos y que pueden concebirse en tanto narrativas de corte material-semiótico que estructuran cómo se simboliza, actúa e interviene en el mundo. Estas narrativas son irreductiblemente colectivas y dan lugar a genuinos choques de mundos en los cuales el diálogo multicultural puede verse obstruido vía numerosas formas de injusticias hermenéuticas o testimoniales. Tener las herramientas necesarias para reconocer estas situaciones es un primer paso para dejar de lado estos desencuentros.

\section{Conclusiones}

Quizás hoy en día resulta por demás complicado imaginar un sujeto colectivo irreductible y que pueda ser presa de injusticias epistémicas como las aquí descritas. 
Empero, un ejemplo sencillo ${ }^{8}$ quizás nos ayude a aterrizar el aparato conceptual desarrollado hasta ahora. Pensemos, por ejemplo, en los patrones textiles que suelen encontrarse en diversas ropas típicas indígenas y que en años recientes han sido objeto de apropiación cultural por parte de modistos que integran estos patrones a sus propios diseños sin observar en ello conflicto ético alguno. Un ejemplo como este ilustra dos puntos de interés. Primero, el sujeto afectado es irreductiblemente colectivo pues no es una injusticia que ha sufrido este o aquel creador indígena sino que es la colectividad entera la que ha sido objeto de un plagio, pues es la colectividad entera la que podría, en cualquier caso, considerarse la propietaria y autora de dichos patrones. Esa misma peculiaridad es precisamente la que podría descalificar a dicha comunidad de cualquier tipo de protección si el concepto de propiedad intelectual se circunscribe a productos creados por personas físicas o morales específicas. Claramente una colectividad como la aquí descrita no es ninguna de estas clases de persona. Peor aun, puede que dicha comunidad carezca de las herramientas necesarias para comprender que ha sido presa de una instancia de apropiación cultural o, en caso de saberlo, que simplemente sea ignorada si decide denunciar. Un ejemplo como este, en su sencillez, quizás aterriza las principales intuiciones del presente texto al ilustrar a qué nos referimos cuando hablamos de sujetos irreductiblemente colectivos y cómo es que estos pueden sufrir injusticias. El caso que aquí nos ha interesado implicaría no ya los textiles sino las formas en las cuales se ha tejido una cosmovisión en torno a la naturaleza que es propia de dicho colectivo.

Dicho esto, y a modo de corolario, resta únicamente decir que a lo largo del presente texto se ha buscado articular una propuesta que vincule la moderna discusión en torno a la injusticia epistémica en sus muy diversas variedades, por un lado, con diversos aspectos que estructuran la relación ser humano-naturaleza y en los cuales el conocimiento es un elemento central, por otro. Este ejercicio de vincular ambos aspectos ha requerido abandonar los sesgos individualistas e identitarios que hasta ahora han caracterizado la discusión en torno a la injusticia epistémica para dar lugar a un enfoque mucho más colectivista y centrado en las narrativas de corte material-semiótico que estructuran los Mundos-de-la-vida de diversos grupos humanos. En el corazón de este desplazamiento yace la intuición de que la crisis ambiental contemporánea requiere, de entre muchas cosas, de un diálogo multicultural serio en el que se retomen, por un lado, los conocimientos $y$, por otro,

8 Este ejemplo está inspirado en un incidente verídico. Véase: https://elpais.com/elpais/2019/06/12/estilo/1560295742_232912.html (consulta: 21/04/2020). 
los testimonios de diversos pueblos para así elaborar diagnósticos y remedios que atiendan a la variedad de posiciones involucradas. La importancia de este esfuerzo se ha ejemplificado en el presente trabajo al hacer ver cómo la injusticia epistémica puede hacerse presente ya sea como una afectación a la labor cognitiva o como una falla en la justicia distributiva; en ambos casos esto propicia situaciones inequitativas que terminan por dañar a alguien y que, al mismo tiempo, bloquean nuestra capacidad de comprender las dinámicas cognitivas involucradas en la relación ser humano-naturaleza en el contexto de la crisis ambiental.

\section{Agradecimientos:}

Se agradece el apoyo del Proyecto PAPIIT IN400318 "Ecología Queer y Filosofía Ambiental” otorgado por la Universidad Nacional Autónoma de México.

\section{Referencias:}

Alaimo, Stacy y Susan J. Hekman (eds.) 2008 Material feminisms, Bloomington, Indiana University Press. Bagemihl, Bruce

1999 Biological exuberance: Animal homosexuality and natural diversity, Nueva York, Macmillan.

Bal, Mieke

2009 Narratology: Introduction to the Theory of Narrative, Toronto, University of Toronto Press.

Brosius, J. Peter.

1997 "Endangered forest, endangered people: environmentalist representations of indigenous knowledge", Human Ecology, 25(I), pp. 47-69.

Collins, Harry y Robert Evans

2009 Rethinking Expertise, Chicago, University of Chicago Press.

Crenshaw, Kimberlé

199I "Mapping the margins: Intersectionality, identity politics, and violence against women of color", Stanford Law review, vol. 43, Pp. I24I-I299.

Cruz Parcero, José Antonio

2007 El lenguaje de los derechos: ensayo para una teoría estructural de los derechos, Madrid, Trotta. 
Dotson, Kristie

$201 \mathrm{I}$ "Tracking epistemic violence, tracking practices of silencing", Hypatia, 26(2), pp. 236-257.

Fricker, Miranda

2006 "Powerlessness and social interpretation", Episteme, 3(I-2), pp. 96-Io8.

Fricker, Miranda

2007 Epistemic injustice: Power and the ethics of knowing, Oxford, Oxford University Press.

Gaard, Greta

I997 “Toward a queer ecofeminism”, Hypatia, I2(I), pp. II4-I37.

Guerrero Mc Manus, Siobhan

2018 "El pánico y tus ojos que me sueñanः etnografía afectiva de un tránsito de género", en Alba Pons y Siobhan Guerrero (coords.), Afecto, cuerpo e identidad: reflexiones encarnadas en la investigación feminista, México, IIJ-UNAM, pp. 99-I3O.

Guerrero Mc Manus, Siobhan y Leah Muñoz Contreras

2018 "Epistemologías transfeministas e identidad de género en la infancia: del esencialismo al sujeto del saber", Revista Interdisciplinaria de Estudios de Género, El Colegio de México, 4, I4 de mayo, e-I68.

Guerrero Mc Manus, Siobhan y Agustín Mercado Reyes

2019 "Mundos en colisión: antropoceno, ecofeminismo y testimonio", Sociedad y Ambiente, 19, pp. 7-29.

Haenn, Nora, Richard Wilk y Allison Harnish

2016 The environment in Anthropology, Nueva York, New York University Press.

Haraway, Donna

2013a Primate visions: Gender, race, and nature in the world of modern science, Nueva York, Routledge.

Haraway, Donna

2013b Simians, cyborgs, and women: The reinvention of nature, Nueva York, Routledge.

Harman, Graham

2018 Object-oriented ontology: A new theory of everything, Londres, Penguin UK.

Hochman, Adam

2019 "Racialization: A defense of the concept", Ethnic and racial studies, 42(8), pp. I245-I262. 
Kidd, Ian James, José Medina y Gaile Pohlhaus

2017 The Routledge Handbook of Epistemic Injustice, Nueva York, Routledge.

Kosek, Jake

2006 Understories: The political life offorests in northern New Mexico, Durham, Duke University Press.

Kusch, Martin

2004 Knowledge by agreement: The programme of communitarian epistemology, Londres, Oxford University Press.

Marder, Michael

2014 Phenomena-critique-logos: The Project of Critical Phenomenology, Londres, Rowman \& Littlefield International.

Mascia-Lees, E. Frances y Nancy J. Black

2016 Gender and Anthropology, Nueva York, Waveland Press.

Mortimer-Sandilands, Catriona y Bruce Erickson (eds.)

2010 Queer ecologies: Sex, nature, politics, desire, Bloomington, Indiana University Press.

Pohlhaus, Gaile

2017 "Varieties of Epistemic Injustice", en I. J. Kidd, J. Medina y G. Pohlhaus (eds), The Routledge Handbook of Epistemic Injustice, Nueva York, Routledge, pp. 13-26.

Proctor, Robert y Londa Schiebinger

2008 Agnotology: The making and unmaking of ignorance, Stanford, Stanford University Press.

Richards, Robert J.

1992 "The structure of narrative explanation in history and biology", History and evolution, Albany, Suny Press, pp. 19-53.

Roth, Paul A.

I989 “How narratives explain”, Social Research, 56(2), verano, pp. 449-478.

Roth, Paul A.

2017 "Essentially narrative explanations", Studies in History and Philosophy of Science Part A, 62, pp. 42-50.

Roughgarden, Joan

2013 Evolution's rainbow: Diversity, gender, and sexuality in nature and people, Los Ángeles, University of California Press.

Rouse, Joseph

1994 Engaging science: How to understand its practices philosophically, Nueva York, Cornell University Press. 
Shieber, Joseph

2015 Testimony: A philosophical introduction, Nueva York, Routledge.

Thomas, Julia A.

2017 "Historia económica en el Antropoceno: cuatro modelos", Desacatos, 54, pp. 28-39.

Tsing, Anna

20II Friction: An ethnography of global connection, Princeton: Princeton University Press.

Wilson, David S.

2005 "Evolutionary social constructivism", en J. Gottschall y D. S. Wilson (eds.), The Literary Animal: Evolution and the Nature of Narrative (Rethinking Theory), Nueva York, Northwestern University Press, pp. 20-37.

Siobhan Guerrero Mc Manus

(CDMX, 198I) estudió biología en la Facultad de Ciencias de la Universidad Nacional Autónoma de México y es maestra y doctora en Filosofía de la Ciencia también por la misma universidad. Actualmente es investigadora titular A en el Centro de Investigaciones Interdisciplinarias en Ciencias y Humanidades (CEIICH-UNAM). Sus áreas de especialidad son (i) los estudios de género y ciencia, (ii) la filosofía de la biología, (iii) el transfeminismo y, (iv) la filosofía del sujeto. Es Nivel I del Sistema Nacional de Investigadores. En 2018 fue galadornada con el premio Distinción Universidad Nacional para Jóvenes Académicos.

Citar como: Siobhan Guerrero Mc Manus (202I), “Injusticias epistémicas y crisis ambiental”, Iztapalapa. Revista de Ciencias Sociales y Humanidades, núm. 90, año 42, enero-junio de 2021, ISSN: 2007-9176; pp. 179-204. Disponible en <http://revistaiztapalapa.izt.uam.mx/index.php/izt/issue/archive $>$. 